\title{
Ten Salient Practices for Mentoring Student Research in Schools: New Opportunities for Teacher Professional Development
}

\author{
Helen Walkington $^{1} \&$ Elizabeth A. C. Rushton ${ }^{2}$ \\ ${ }^{1}$ Deparment of Social Sciences, Oxford Brookes University, Oxford, UK \\ ${ }^{2}$ School of Education, Communication and Society, King's College London, London, UK \\ Correspondence: Elizabeth A. C. Rushton, School of Education, Communication and Society, Waterloo Bridge \\ Wing, King's College London, SE1 9HN, UK. Tel: 44 -788-054-5467. E-mail: elizabeth.rushton@kcl.ac.uk
}

Received: September 14, 2019

Accepted: October 4, 2019 Online Published: October 11, 2019

doi:10.5539/hes.v9n4p133

URL: https://doi.org/10.5539/hes.v9n4p133

\begin{abstract}
This paper proposes ten salient practices of research mentoring activity in high school settings for teachers and technicians based upon survey and interview findings from 96 English and Scottish high school teachers from STEM disciplines, working in research collaborations with scientists. Mentoring high school research provides career development, with teachers identifying new aspects to their professional roles including 'teacher researcher', 'teacher scientist' and 'teacher mentor'. This study suggests the potential for using the ten salient practices to initiate individual teacher reflection and wider professional development, and, a way of framing and disseminating effective practice across the school sector.
\end{abstract}

Keywords: student research, mentoring, science education, teachers

\section{Introduction}

Over the last three decades, researchers have documented opportunities and approaches that actively involve young people in practical independent research projects (IRPs) as part of their high school ${ }^{1}$ science education (Albone, Collins \& Hill, 1995; Bell, Urhahne, Schanze \& Ploetzner, 2010; Bennett, Dunlop, Knox, Reiss \& Torrance-Jenkins, 2018; Lombardi, 2007; Reiss, 1992). Bennett et al. (2018) describe IRPs as being student-led, extended, practical investigations where the student and teacher do not know exactly what the investigation will result in. As a mode of working, IRPs tend to be predominantly extra or co-curricular, and undertaken by high school students (Bennett et al., 2018). The role of teachers as mentors in school science activities including IRPs, and inquiry-based learning has received little attention in the literature to date (Rushton \& Reiss, 2019). When describing authentic school science activities, Roth (1995) identifies the importance of teachers as part of a wider community of inquiry, where students can share ideas and resources and draw on the expertise of more knowledgeable members.

Engaging in research is an expectation for most undergraduate degree programmes, and the benefits of mentored research are well documented at higher education level (Gillies \& Marsh, 2013; Healey \& Jenkins, 2009; Hensel, 2012; Kuh, 2008; Lopatto, 2010) with this activity being considered a 'high impact' educational practice (Elgren \& Hensel, 2006; Elrod, Husic, \& Kinzie, 2010; Kuh \& O’Donnell, 2013; Lopatto, 2010). However, to date, little attention has been paid to the role and practice of teachers involved in school-based science research (Rushton \& Reiss, 2019). This current study contributes to this research area, providing a framework for mentoring school-student research drawn from a synthesis of effective mentoring practice from higher education (Shanahan, Ackley-Holbrook, Hall, Stewart \& Walkington, 2015; Walkington, Hall, Shanahan, Ackley \& Stewart, 2018) combined with new insights from the experiences of high school teachers.

Mentoring at undergraduate level has been defined by Osborn and Karukstis (2009) as,

A serious, collaborative interaction between the faculty mentor and the student, in which the student is intellectually engaged in the scholarly problem or project. The faculty mentor guides the student into deeper intellectual engagement over the course of their collaboration. The faculty mentor's attention is equally focused on the student's development and on the results or product of the scholarly or creative project. (p. 42).

Alongside this, Thiry and Laursen (2011) identified three forms of support which undergraduate research 
mentors provide for student researchers in bringing them into a scientific community of practice: intellectual support (with the research process); personal and emotional support (being available to students and taking an interest); and support with professional socialisation (over and above disciplinary knowledge and skills passing on the values and norms of scientific endeavour).

While teacher and technician support for research projects in high schools will be highly likely to involve intellectual support, and in isolation could be termed 'supervision' rather than mentoring, the personal and emotional or 'whole student' support and professional socialisation as a scientist are perhaps less frequently anticipated forms of practice at school level. However, engaging in school-based mentoring as described in this article clearly moves from a simple teacher - student relationship to research mentoring and in some cases adopts a co-researcher model. In outlining ten practices practiced by teachers we provide evidence of all three forms of Thiry and Laursen's (2011) support given by teacher-mentors.

The publication of ten salient practices for undergraduate research mentoring, based on a large-scale literature review (Shanahan et al., 2015), revealed an effective pedagogy of mentored research which applies across disciplines, institution types and countries. Subsequent research with award-winning undergraduate research mentors internationally has begun to elicit nuances to this pedagogy, guided by a common set of underlying values that mentors hold (Walkington, Stewart, Hall, Ackley \& Shanahan, 2019), which manifest as an ability to establish and sustain a sense of challenge, while maintaining meaningful engagement and a sense of achievement amongst students. The empirical data set has revealed how award-winning mentors see the future of mentored research, particularly their commitment to broadening participation amongst a greater student demographic, and democratisation of the research process (Shanahan, Walkington, Ackley, Hall \& Stewart, 2017). Furthermore, undergraduate research mentoring has been conceptualised as a professional development activity when a co-mentoring model has been adopted (Ketcham, Hall, Fitzgibbon \& Walkington, 2018). The positive and negative impacts of student research mentoring activity have also been explored in relation to career and identity development for faculty members (Hall, Walkington, Shanahan, Ackley \& Stewart, 2018a). There have been accounts of how mentoring practice varies across different countries (Larson, Partridge, Walkington, Wuetherick \& Moore, 2018), as well as utilisation of the ten salient practices to consider curriculum redesign to ensure a high-quality mentored experience where students receive research mentoring outside their own institution (Hall et al., 2018b). The ten salient practices for undergraduate research mentoring have provided the theoretical frame against which to explore teacher practices in mentoring science research in high school contexts. This paper now describes the context of authentic research in schools, and specifically the work of the Institute for Research in Schools (IRIS).

The Institute for Research in Schools (IRIS) is a UK-based charity launched in March 2016 to develop an approach to school education where research is a key element of STEM (science, technology, engineering and mathematics) learning, offering opportunities for students to work on genuine problems (Parker, Fox \& Rushton, 2018; Rushton \& Reiss, 2019). This is founded on a social constructivist approach to learning, where students are supported by their peers, teachers and other collaborators, to develop both their understanding of science and to further science itself (Parker et al., 2018; Rushton \& Reiss, 2019). The role of the high school teacher is to encourage, support and facilitate their students' participation. Students and teachers from over 300 high schools located across England and Scotland are currently involved in one or more of eight STEM research projects developed by IRIS, in conjunction with researchers based in universities and research centres (IRIS, 2019). IRIS supports schools in building research networks and provides access to data and experimental equipment.

The IRIS project CERN@school provides a representative example of the types of engagement and collaborations between school student researchers, teacher-mentors and research scientist partners across the wider group of projects experienced by teachers in this study.CERN@school lends a radiation detector and software to schools which enables the visualisation of alpha, beta and gamma radiation particles (Parker, Thomas, Rushton \& Hatfield, 2019). Since 2008,CERN@school has included more than 300 schools, hundreds of teachers and technicians, and involves thousands of students. Resource materials and online support has been developed by IRIS and high school teachers and technicians have used the technology both to support curriculum activities and provide stimulus for student research, which has included research into solar radiation levels (Furnell, Shenoy, Fox \& Hatfield, 2018).CERN@ school research projects have led to the development of the Langton Ultimate Cosmic ray Intensity Detector (LUCID) project, which has enabled students to develop an understanding of radiation in space and large-scale data analysis resulting in co-authored peer-reviewed research, mentored by teachers and technicians (Furnell et al., 2018; Whyntie \& Harrison, 2014; 2015). In these ways, students, teachers and technicians worked collaboratively to produce new understandings and, in some cases, co-publish research outputs. 
This paper outlines ten salient practices for teachers mentoring high school student researchers. The practices are described in a sequence which attempts to mirror the research process, beginning with the planning and scaffolding required to initiate research projects and ending with the research dissemination phase. The practices presented here are developed using data gathered from high school contexts, considering differences between school and university education where levels of expectation for students to engage in primary research differ. For example, teachers are, in the main, partnering with students in research, which is new to both partners, a situation different to most undergraduate settings, where most faculty members are likely to have knowledge and expertise in the particular area of research. However, teachers in schools may engage with multi-generational projects, becoming increasingly familiar with a research area where school student cohorts are 'passing through'. Yet there are also clear similarities between undergraduate and high-school research, in that many students take part in the research experiences voluntarily, that 'authentic' research (i.e. making a genuine contribution to knowledge) can be a shared experience between a mentor and mentee(s), and that students can take on greater control and ownership throughout the research process.

\section{Method}

This study aimed to elicit detailed descriptions of practice from teachers who have acted as research mentors to high school science students in order to compare this with research mentoring practice at undergraduate level. A qualitative methodological approach was adopted to elicit descriptions of teachers' practice, combining in-depth interviews with open responses to an online survey. Interviews were conducted with a selection of experienced and highly engaged teachers. The open format of data collection with the most experienced mentors was then interrogated to highlight the practices that were least frequently mentioned, and which formed the basis of a targeted survey on specific practices sent to all teachers on IRIS projects. The two data collection phases are described in turn.

The first phase of data collection took place between January and May 2018 and involved semi-structured interviews, with the aim of eliciting rich descriptions from 'teacher mentors' of their own practice. The interviews were carried out with high school teachers who had participated as mentors in one of the projects being offered in collaboration with IRIS and was focussed on those teachers who had at least six months experience of working on IRIS research projects and who attended IRIS student research conferences with their students. At the time, four teachers had a special role as 'hub teachers' with the remit to share their practice across a regional network of schools and to mentor other less experienced teachers. Nineteen teachers agreed to be interviewed, including two hub teachers. Nine interviews were conducted in Local Authority comprehensive high schools in England and Scotland, four in Local Authority selective grammar schools in England, four in fee-paying independent high schools in England and two in Academies, one in England and one in Scotland. Interviews lasted between 20-45 minutes and teachers were asked questions which included asking them to describe their mentoring practice; how their mentoring practice changed over time; aspects of mentoring that they found challenging; and, how the specifics of the research project they participated in shaped their mentoring practice. Demographic details of the interviewees are presented in Table 1. The 19 interviewees were atypical in being overrepresented with respect to doctoral and postdoctoral science research experience.

Table 1. Subjects taught, teaching experience and current management roles of the teacher-mentor interviewees $(\mathrm{n}=19)$

\begin{tabular}{llll}
\hline & Female & Male & Total \\
\hline Main subject taught & & & \\
Biology & 3 & 4 & $\mathbf{7}$ \\
Chemistry & 2 & 1 & $\mathbf{3}$ \\
Physics & 4 & 5 & $\mathbf{9}$ \\
Number of years teaching experience & & & \\
<5 years & 3 & 1 & $\mathbf{4}$ \\
6-11 years & 3 & 3 & $\mathbf{6}$ \\
12-17 years & 0 & 3 & $\mathbf{3}$ \\
$>18$ years & 3 & 3 & $\mathbf{6}$ \\
Mean (standard deviation) & $13(10.4)$ & $15(8.9)$ & $\mathbf{1 4}(9.4)$ \\
Has a PhD in a science subject & 4 & 3 & $\mathbf{7}$ \\
Has post-doctoral research experience & 1 & 2 & $\mathbf{3}$ \\
\hline
\end{tabular}

Applied thematic analysis (Guest, MacQueen \& Namey, 2012) was used to identify practices described by the 
teacher-mentors, framed using the ten salient practices of Shanahan et al. (2015) and Shanahan, Ackley-Holbrook, Hall, Stewart and Walkington (2016) through a process of double-blind coding, involving both authors. It became apparent that teachers were employing all ten of the salient practices that characterise effective mentoring for undergraduates, but in ways unique to schools.

The narrative descriptions of practice from phase one provided more detail in relation to some practices than others. More targeted questioning through the development of an online survey allowed the researchers to gain a broader insight into all the ten practices, as well as the context-specific opportunities of teacher-mentors across all schools involved in IRIS projects. In phase two, an online survey was emailed to all teacher-mentors who had been actively working with IRIS for at least three months based in England $(n=164)$, Scotland $(n=14)$ and Wales $(\mathrm{n}=1)$. The survey questions were structured around salient practices $2,5,6,8,9$ and 10 to identify how these practices were implemented across a variety of school contexts and to explore opportunities for targeted support. 77 teachers working in 76 schools based in Scotland and England responded (43\%), all of whom had participated in research projects developed by IRIS.

\section{Results}

Data from both the interviews and the survey responses (Table 2) were linked to the ten salient practices and, taken as a whole, they form a pedagogy of mentored authentic science research for high-school science projects (Table 3). Teachers reported working mostly with students aged 16-18 years (49\%), 14-15 years (29\%) and 11-13 years $(22 \%)$. Examples of all ten practices were given during the interviews, with practices 1, 3, 4, and 7 described in the most detail. Practices 6,9 and 10 were only outlined by half of teachers in both the survey and the interviews (Table 2).

Table 2. Results from an online survey of high school teachers to gather details of practices 2, 5, 6, 8, 9 and 10 $(\mathrm{n}=77)$

$\begin{array}{ll}\text { Salient Practice } & \begin{array}{l}\text { Number of teachers } \\ \text { that do include this practice }\end{array}\end{array}$

Number of teachers Number of respondents

who do not include who did not answer the this practice question

\begin{tabular}{|c|c|c|c|c|}
\hline \multicolumn{5}{|c|}{ 2. Set clear and well scaffolded expectations for student researchers. } \\
\hline \multirow{4}{*}{$\begin{array}{l}\text { c. Gradually give students more } \\
\text { independence. }\end{array}$} & Total: & 42 & 26 & 9 \\
\hline & CREST: & 18 & & \\
\hline & EPQ: & 12 & & \\
\hline & Other: & 12 & & \\
\hline \multirow{6}{*}{$\begin{array}{l}\text { d. Outline expectations by creating } \\
\text { research group 'rules' with students } \\
\text { that they sign up to at the outset. } \\
\text { 5. Build a sense of community } \\
\text { among the members of the } \\
\text { research team. }\end{array}$} & Total: & 16 & 50 & 11 \\
\hline & Total: & 42 & 24 & 11 \\
\hline & Trips: & 16 & & \\
\hline & Speakers: & 9 & & \\
\hline & $\begin{array}{l}\text { Journal } \\
\text { Clubs: }\end{array}$ & 5 & & \\
\hline & Other: & 12 & & \\
\hline \multirow{5}{*}{$\begin{array}{l}\text { 6. Dedicate time to one-to-one, } \\
\text { hands on mentoring. } \\
\text { 8. Support students professional } \\
\text { development through networking } \\
\text { and explaining the norms of the } \\
\text { discipline. }\end{array}$} & Total: & 33 & 34 & 10 \\
\hline & Total: & 41 & 21 & 15 \\
\hline & $\begin{array}{l}\text { Work } \\
\text { experience: }\end{array}$ & 25 & & \\
\hline & $\begin{array}{l}\text { Build } \\
\text { networks: }\end{array}$ & 11 & & \\
\hline & Other: & 5 & & \\
\hline \multirow{4}{*}{$\begin{array}{l}\text { 9. Create opportunities for peer } \\
\text { and near-peers to learn mentoring } \\
\text { skills and give more students } \\
\text { access to research opportunities. }\end{array}$} & Total: & 32 & 30 & 15 \\
\hline & $\begin{array}{l}\text { Older/former } \\
\text { students: }\end{array}$ & 20 & & \\
\hline & $\begin{array}{l}\text { University } \\
\text { students: }\end{array}$ & 5 & & \\
\hline & Other: & 7 & & \\
\hline 10. Encourage students to share & Total: & 25 & 26 & 13 \\
\hline
\end{tabular}




\begin{tabular}{l}
\begin{tabular}{lll}
\hline their findings and provide & School & 15 \\
guidance on how to do so & events: \\
effectively in presentations and in & External & 10 \\
writing. & events:
\end{tabular} \\
\hline
\end{tabular}

Here we present the ten practices as summarised in Table 3, and the ways in which they are practised and adapted in school contexts by 'teacher mentors'.

Table 3. Ten Salient Practices of Teacher-Mentors for school-based student research

1. Do strategic pre-planning to be ready to respond to students' varying needs and abilities throughout the research process.

a Invest time early in the process for project selection, pre-teaching and student recruitment.

b Consider wide variability in student age, motivation and skills.

c Set achievable timelines that reflect curricular requirements.

d Do not underestimate students' abilities to do authentic scholarship.

2. Set clear and well-scaffolded expectations for student researchers.

a Attend to fluctuating needs of students at different points in the process.

b Provide strong support early on.

c Gradually give students more independence (e.g. use external frameworks such as EPQ and CREST awards).

d Outline expectations by creating research group 'rules' with students that they sign-up to at the outset.

3. Guide students in the technical skills, methods, and techniques of conducting research in the discipline.

a Introduce students to the expectations of scientific endeavour and research in the discipline.

b Guide students through the technical practices needed to support project goals (e.g., protocols for labs, equipment, databases, software).

c Emphasise the importance of ethical standards (e.g. human participants) and safety (e.g. laboratory, fieldwork).

4. Balance rigorous expectations with emotional support and appropriate personal interest.

a Provide positive yet constructive feedback.

b Remain approachable to minimise anxiety and boost confidence.

c Adapt your emphasis to suit student needs.

5. Build a sense of community among the members of the research team.

a Build trusting interpersonal relationships in the team.

b Practice intentional team development.

c Spread the benefits of research via peer- and near-peer mentoring, allowing student mentors to develop skills and pedagogy.

d Engage the team in common interest, non-research activities to foster connections (e.g. visits and trips that involve social/recreational time).

6. Dedicate time to one-on-one, hands on mentoring.

a Minimise false assumptions regarding ability and progress.

b Provide personalised guidance and advice (e.g. drop-in sessions at lunchtime; use external frameworks including EPQ and CREST awards).

7. Increase student ownership of the research over time.

a Explain how student tasks relate to larger project goals.

b Welcome student opinions about their work.

c Listen with patience and openness.

d Foster autonomy by giving students ownership of specific tasks and important aspects of the overall project.

8. Support students' professional development through networking and explaining the norms of the discipline.

a Provide networking opportunities by introducing students to researchers and other professionals (e.g. organise visits to university/specialist libraries).

b Provide networking opportunities in informal environments (e.g. invite speakers to school and have informal Q\&A with students).

9. Create opportunities for peer and near-peers to learn mentoring skills and give more students access 


\section{to research opportunities.}

a Create intentional opportunities for peers and near-peers to learn mentoring skills (e.g. school science ambassador scheme).

b Model the characteristics of a successful researcher, as well as of a successful mentor.

c Provide guidance for expectations of peer relationships (e.g. school mentor handbook/training).

\section{Encourage students to share their findings and provide guidance on how to do so effectively in presentations and in writing.}

a Develop avenues for dissemination so that students understand what it means to be a scholar (e.g. write articles for local paper; create posters of student work to display in school).

b Encourage students to present work to peers, experts, community as a way to develop oral and written communication skills (e.g. local competitions; assemblies in other schools; present to parent groups).

\subsection{Ten Salient Practices for Mentoring High-school Science Projects}

3.1.1 Do Strategic Pre-planning to be Ready to Respond to Students' Varying Needs and Abilities Throughout the Research Process

It is challenging for teachers to anticipate pre-planning aspects of authentic research where there is a lack of familiarity with a specific research area and a genuine sense of 'stepping into the unknown' with students. However, school students represent a range of abilities and require strong support to access the knowledge, skills and concepts needed to engage actively at the outset of new research. This might be because they have not yet encountered material in the high school curriculum or because the research project extends into areas beyond the curriculum. In addition, teachers of secondary science while having a good knowledge of a broad science curriculum, would be unusual in having experience of science research in an area that they are now actively researching with their students. One form of pre-planning is appropriate project selection and student recruitment. In the main, teachers choose the research projects and lead on student recruitment. Recruitment is predominantly based upon identifying student interest through open invitations, rather than proven academic ability, but can also be constrained by structural issues, such as timetabling. Students need to be available at the same time that teachers can provide access to the research projects e.g. after school or during lunch time. However, for those teachers with a research background i.e. $\mathrm{PhD}(\mathrm{n}=7)$ and post-doctoral researchers $(\mathrm{n}=3)$ (Table 1), pre-planning in terms of pre-teaching scientific content was carried out. For example, teachers introduce some of the core knowledge to their whole class prior to starting the research project, so that students have the necessary background to begin the research. One teacher who mentored a genomics project noted this pre-teaching:

The logistics was an interesting issue - over half of the students who showed an initial interest had not done that kind of advanced genetics at all...so I started with some introductory talks for example, this is DNA, this is what you need to know, introducing them to some of the key vocabulary and ideas... (Peter, Biology teacher)

Another aspect of pre-planning is working to timelines, where teachers try to align what can be a messy or jerky research journey to appropriate school timescales. Timelines for the research may be set externally where students are working to external qualification frameworks such as the Extended Project Qualification (EPQ) and CREST awards ${ }^{2}$. In this case, the role of teacher-mentors is to help students stay on schedule, although this is something that teachers noted students took increasing responsibility for as the research progressed. Although teacher-mentors and technicians were often learning alongside their students, they maintained a positive attitude that with time and preparation, learning would be effective, and the project outcomes would be met.

\subsubsection{Set Clear and Well-scaffolded Expectations for Student Researchers}

Teachers with more than two years of experience in research with high school students tend to set clear expectations and provide scaffolding. Teachers provide strong support through setting homework tasks as prompts or starter activities for research:

I work with the students in a very different way in the research groups, we are working together sometimes, I give them a prompt, an idea then they go with it...I give them homework questions to think about and then they come back, and they have taken it further on and some things are completely unexpected. Other times I am completely in the background. (Keith, Biology teacher)

Teachers break down research into more manageable tasks for students. When working with students to prepare for a conference presentation for example, teachers guide students by helping them divide the content into sections for individual students to prepare. Teachers also provide opportunities for students to rehearse 
presentations to audiences of student groups and other teachers. Some teachers also prepared students who were presenting at conferences by describing the environment and audience in a way that highlighted the professional nature of the event to students so that they understood the expectations their teacher had of them, including implicit expectations about how to present and to operate effectively in a new environment. Teachers provided examples of previous work (e.g. high-quality research posters) to give students a framework and to set high expectations. Teachers also used external frameworks, with CREST awards and EPQs the most common examples from the survey (Table 2), to give students additional guidance and support in how to undertake scientific research: 'I adapted the project to make it more pupil led, and the students were able to submit their work for the Bronze CREST award'. (Carol, Biology teacher).

Only some teachers described using learning contracts or agreements when working with student researchers (Table 2), suggesting that rules and contracts are not part of their 'informal', 'after-school' approach to research projects and that their research with students 'operates on the basis of students' motivation' (Arnold, Physics teacher). When teachers do employ agreements, they often link them closely to the curriculum guidelines associated with external frameworks (Table 2), e.g. the course specification for the EPQ, although one teacher shared their contract which included an expectation that students mentored younger students as part of the agreement. In this way, the teacher integrated their practice of setting clear expectations (salient practice 2) with providing opportunities for student researchers to be involved with peer and near-peer mentoring (see salient practice 9 below).

\subsubsection{Guide Students in the Technical Skills, Methods, and Techniques of Conducting Research in the Discipline}

A starting point for teachers when encouraging students to explore and experience science research is the introduction of Journal Clubs. These sessions are often held at lunchtimes or during after school sessions where students, usually aged 14-18 years, read and discuss articles with their teachers. Journal Clubs are used to meet several objectives simultaneously. Firstly, to understand current research, secondly, to consider links between this current research and topics in the school science curriculum. Thirdly, to understand the scientific method through how a journal article is structured from the wider context and the need for the research, to results, discussion and next steps. Fourthly, mentors report using the further questions offered at the end of articles to position their students, 'to be in the space where they are scientists that could continue the research, to try to answer those questions, or others they may have' (Natalie, Chemistry teacher). Teachers that implement Journal Clubs also describe the progression of these activities from ones that are initially teacher-led, with teachers selecting the articles and providing verbal and/or written framework for discussion, to ones that are led by students, discussing the research that links to their own research project and interests. In this way, the teachers are modelling how to use wider research to inform new research endeavours and initiatives. This progression from teacher to student-led sessions is also a way to model salient practice 7, where student ownership of the research increases over time.

As part of guiding students in this practice, teachers explain to their students how scientific research and inquiry works, emphasising that they (the teacher) do not have the answers and supporting students to develop the thinking skills required to progress through different phases of research:

I like telling them that I don't know what we are expecting and I don't know how we are going to do it. For them that is very new. They see us as people that say, 'this is how you do the experiment, we know what we are expecting' and we can't tell them that for this. I like that because you see the kids develop from it. They are seeing it for themselves, 'Ok this didn't work, why was that? Right, I am now going to go away and look at this'. That is the experience of real science. (Michelle, technician)

Teachers build a rapport with their students when they guide them through some technical aspects by sharing that they themselves are learning something new and are experiencing anxiety:

I showed the students a screen shot of the software and said to them, 'if that terrifies you don't worry, it terrifies me, I haven't a clue what to do or how this works, but we can learn together. (Peter, Biology teacher)

Some teachers do not teach the technical skills themselves but provide guidance to students as they learn skills from other partners they work with e.g. undergraduate students. Teachers use practical experiment time in the curriculum to build a scaffold for students so that they have the confidence to participate in the elective, non-compulsory research activities. Teachers also leverage the high-tech nature of some of the research equipment to encourage students to participate in research. Teachers and technicians highlight the ethical areas that need to be considered in research, both through discussions of published research but also through the planning and experimental phases of research projects which may include human participants or require 
field-based data collection.

\subsubsection{Balance Rigorous Expectations with Emotional Support and Appropriate Personal Interest}

Teachers emphasise that all aspects of scientific endeavour are part of a rigorous process and that students are going to have to become comfortable with not knowing an answer and working out what an answer might be from the information they have currently.

...what I am trying to do as a teacher, what I want to do, is make them feel comfortable feeling uncomfortable. So I tell them... they can't just say, 'I don't know' because I will say, 'I am not leaving until I get some sort of answer out of you that makes some sort of sense, so you might as well dig in for the long haul. (Natalie, Chemistry teacher)

The point here is to support students as they make a transition from learning through a transmission model from their teacher, to learning as a co-inquirer, something that prepares students for post-school education and employment. Another example of this transition is to move students from being positioned as learners to that of researchers through dissemination activities. Teachers encourage students to contribute to conferences in a way that engages the conference audience in the students' research. This means giving students explicit feedback about whether their poster submissions are appropriately and concisely sharing their research findings. Teachers also support students in making the most of the conference experience, encouraging them to ask questions of other student researchers and at times brokering that engagement by introducing students to other groups and initiating discussions.

Teachers set high expectations for students by explaining to them at the outset that if they give of their best, they have the capacity to make a valuable contribution e.g. publishing their work in a peer-reviewed journal.

The biggest role for the teachers is to make sure that the students have had the opportunity to work on a project and advance that project to the point where there is sufficient robust work for publication. The paper cannot be written without this. (Toby, Physics teacher)

Teachers take the time to support students through the rigorous process of writing a paper for publication by acknowledging both the challenges and the opportunities that this experience will bring for students. This is achieved in part by explaining to students that what they are experiencing reflects the reality of science and that they are part of a global science community. Teachers provide support for students when they persevere through the challenges presented by publication and perhaps initially struggle with the high level of expectations and attention to detail required by publication.

One teacher gave the example of students needing emotional support in order to excel as researchers when they were invited to share their research with the wider public as part of a two-day event at their local science centre. This opportunity to engage the public with their research clearly came from rigorous expectations, but in order for the students to be able to achieve this they needed the support of their teacher in terms of practising, confidence building, structuring the day and managing time and sharing different roles amongst students.

\subsubsection{Build a Sense of Community Among the Members of the Research Team}

Teachers recognise that through research they, and their students, have the opportunity and capacity to be a contributing part of a wider research community that is beneficial to all partners. Teachers leverage a network of researchers across different institutions including undergraduate students, academics and IRIS staff: 'I am connected to a network of university researchers, industry, people with equipment, chemicals, things I need to be able to put projects together for my students.' (Keith Biology teacher) and, 'The students are part of a research community in school, and it was so important to be connected with researchers.' (Sally, Biology teacher). Teachers are able to create spaces beyond the official timetable to develop a research team and community e.g. through establishing a journal or after school club.

Peer and near-peer mentoring in high school research teams was relatively common practice (Table 2) and:

The research project has 10 students [aged 11-13 years], 50:50 boys and girls, they are a big range of abilities and personalities, they were self-selecting so they were interested enough to participate and we also have six girl sixth formers and some of them are really good and they really push the project forward and they are so good at managing the younger groups and saying, 'right, you're doing this, you've got to go away and find this. (Keith, Biology teacher)

Some of the school-based research projects have evolved over a number of years, involving multiple generations of students. Teachers noted how motivated students were to work together, those with greater experience helping those with less, leading to 'near peer' or 'vertical' mentoring communities. For long standing projects, e.g. 
CERN@school (10 years), teachers have actively recruited former CERN@school alumni (e.g. undergraduate, doctoral and post-doctoral researchers) to mentor current school students e.g. writing peer-reviewed papers using data from projects that they themselves contributed to whilst at school (Furnell, Shenoy, Fox \& Hatfield, 2019; Hatfield et al., 2018; 2019).

When responding to the survey, two thirds of teachers and technicians described how they built a sense of community among their research group through research related trips (e.g. a visit to their local university, science exhibitions) and organising external speakers to visit the school (e.g. STEM Ambassadors, local conservation groups, university speakers). Several respondents collaborated with other schools and used journal clubs or afterschool clubs to develop a sense of community. Much less frequently teachers described social events, for example, 'We meet for lunch at the end of term in a local restaurant' (Kera, Biology teacher) or incorporating a social aspect to a research focused event, 'If the students are delivering a public talk, staff and pupils usually...go for a coffee and chat in a local café' (Christian, Physics teacher). Many more teachers suggested that they intended to include a social aspect in the future.

\subsubsection{Dedicate Time to One-on-one, Hands on Mentoring}

Teachers and technicians use one-to-one mentoring to encourage students to persevere during challenging phases of research, coaching individuals to go beyond their own expectations of their ability. Teachers provide additional support for students who are anxious about particular phases of research, for example, extra rehearsals with shy students preparing to present at conferences. Technicians describe that they can provide an 'open door policy' during times when students are free (e.g. lunchtime sessions, study periods) which enable them to 'troubleshoot' problems (often with software, equipment) due to the relatively greater flexibility in their working day compared with teachers.

\subsubsection{Increase Student Ownership of the Research over Time}

As indicated in salient practice two, teachers have the expectation that student ownership of research will increase over time. Teachers direct the research at the outset, prompting students through questions and identifying tasks that need completing. Over time, some students take on that role and direct their peers. Ownership of the management and progression of the research can be taken on by some students naturally:

...when I introduce a project...for the first few months it would be all about me saying, 'Have you done this? Have you got this bit of data? Who is looking after this?...But then, with time, without me interfering there would be certain people who would start to take on the leadership role and say, 'Come on guys, we need to do this, and get into pairs and sort that and timetable it', leadership in the practical side. (Natalie, Chemistry teacher)

Teachers hand over parts of the research project to students e.g. presentations to external audiences, which fosters student autonomy and their ownership of project outputs:

We went as a group to the Royal Society to do a poster presentation and talk and they organised it themselves, in terms of slides and talk. My jaw dropped because they had to do [a] workshop ... put together a five-minute presentation of their research that was going to be videoed, and I thought 'I am going to have to take control of this'. [But] it was a student who took control, they made a really funny sketch that really summarised the science so perfectly, I was blown away. (Natalie, Chemistry teacher)

3.1.8 Support Students' Professional Development through Networking and explaining the norms of the discipline

Providing development opportunities for school-based researchers constituted involvement in networking opportunities, preparing to share research findings (e.g. co-producing research papers, posters, or other forms of research dissemination), and helping students to access work experience or placement opportunities. The most common means to develop networking was by introducing students to researchers, whether at school/college through invited talks or in-school sessions with visiting researchers, or externally through site visits. Informal networking can be particularly powerful for students, especially where pupils can identify role models, such as university students who may be easier to identify with than more eminent scientists.

Teachers who had been involved in research with their students for some time were able to create opportunities for their students to share their research (e.g. presenting to primary school groups) and through that build networks with other researchers and engage younger students in scientific endeavour through their experiences. Through creating these opportunities, teachers are explaining to their students the norms of the discipline and the social/professional norms of an academic environment: 
'I build up partnerships with local schools and also universities so that the students can continue to access cutting edge thinking so they can contribute to a community. That is the value of the conferences, students are able to share their knowledge and experience and they understand that they are building this research year on year and this will continue after their year group and it will be based upon the work of others. That is how research works.' (Keith, Biology teacher)

Teachers facilitate networking for students, co-ordinating sessions led by external speakers and intentionally stepping back, allowing their students to engage and build a professional relationship with external speakers and providing follow-up activities for students to make best use of an external speaker's time. Teachers encourage students to share their research at events where they meet scientists and can discuss science as contributing members of the research community. School students require support from teachers and technicians to make best use of networking opportunities at events, with teachers facilitating conversations between school students and PhD students. Brokering opportunities to allow students to ask questions and understand the career paths and experiences of early career researchers that they can identify with is a key element of this practice.

Teachers and technicians frequently support student development, and some achieve this by helping students obtain work experience and research placements (Table 2). Placements varied in length (a few days to 4 weeks) and context (industry, university/research institute laboratory, hospital). External opportunities featured in student professional development and, in addition to work experience and research placements, included supporting students to connect with external scientists, visit specialist libraries, co-publish research papers, and present at external conferences (Table 2). Teachers and technicians provide opportunities for student professional development within the school context, e.g. working with other schools, presenting at school conferences and displaying students' work in school (Table 2).

3.1.9 Create Opportunities for Peer and Near-peers to Learn Mentoring Skills and Give More Students Access to research opportunities

Teachers show students that being a successful researcher is being in an intellectual space where answers are not yet known. One teacher said:

The students are willing to struggle in research projects because...I am saying 'I haven't got the answer, I have got some ideas, but nobody knows, not even these doctors and professors at university, so actually guys you are in the same boat with them, with me' so, I think because there isn't an answer that is known yet, they feel more comfortable with not knowing, it is equal ground. (Natalie, Chemistry teacher)

This modelling of researcher characteristics opens up a space for all participants to become experts and allows mentoring between peers and near-peers to become part of this space, even when younger school students are mentoring older ones, as a result of having developed particular expertise. As school research is predominantly a team activity, teachers frequently incorporate peer mentoring and near-peer mentoring into the delivery of their research activities:

When the year 7s led the GCSE coursework experiments with the primary school students, they were leading the teaching and supporting the students doing the research activities. (Keith, Biology teacher)

The role of teachers in this situation is in ensuring that near and peer mentoring is productive and respectful. Some classrooms had rules on behaviour and expectations. Involving peers or near-peers in mentoring was part of teachers' practice (Table 2). These near peers included older school students, alumni, university students, teachers with research experience and students with research project experience. Less frequently mentioned were partner schools, STEM ambassadors and university academics.

For some teachers vertical mentoring was integral to the research project: 'All the work is carried out across year groups. With the older, longer attending students, mentoring the younger/newer students.' (John, Biology teacher). Whereas other teachers did not delegate the mentoring because they identified it as being a core part of their role, 'I do the mentoring myself. It is part of my supra-curricular offering to the school' (Carol, Biology teacher).

3.1.10 Encourage Students to Share Their Findings and Provide Guidance on how to do So Effectively in Presentations and in Writing

Research dissemination is actively supported by teachers and technicians (Table 2). Examples of this practice included providing templates for posters, running sessions to discuss what makes a good poster, as well as supporting the preparation and rehearsal of presentations. Raising awareness of competitions and avenues outside school for students to share their work e.g. talks to local societies and visits to other schools, were opportunities for dissemination to have greater authenticity. Examples of dissemination within the school 
community included school assemblies, subject societies and science fairs, as well as presentations to visiting schools and parents, with more long term displays of posters in the school. External dissemination was concentrated on large-scale events such as the Royal Society Science EXPO, partner university conferences and the Big Bang Fair: 'They talked about winning the big bang and teen tech to the whole school and will talk about the genome project to encourage the next cohort'. (Kera, Biology teacher). Also:

[We] ensure that there is an outcome of whatever project - even if the experiment aims were not met - e.g. a poster, presenting at assembly etc...enter competitions as appropriate...talk to younger students about their experiences. Publications may be a year or so away given the state of the projects so far. (Joel, Physics teacher)

Just under half of the teachers surveyed had taken their students to conferences. For conference events, where the emphasis is on oral presentations of research, perhaps with poster presentations, teachers distinguished the support that they gave to their research mentees into activities done before, during and after the conference event. Preparing posters and practising presentations was important, with audiences for these practice sessions including parents, other teachers and other students. For example, an English teacher was invited to coach students in presentation skills and how to build a narrative and divide a presentation up into tasks for students, then help them put it back together as a group presentation. Explaining expectations was also important and included time to 'Discuss the benefits of collaboration and communication in science.' (Nathan, Biology teacher). Practise sessions were also used to encourage students that their work was a valuable and high-quality contribution.

During conference events the mentor role switched to a supporting one: 'I make them feel comfortable at the symposium and let them mostly free so they can explore themselves.' (Theo, technician). Introducing students to other people and facilitating conversations to develop networks was also an important role for teachers. Sometimes this was to develop networks with other schools, but also to network with eminent speakers: 'I challenge them to get contact details from speakers (this has been particularly successful) and start to develop their networks with pupils from other schools where appropriate.' (Joel, Physics teacher). Enabling students to be independent and 'step up to the challenge' was also important for teacher - mentors. Following conference events, work such as raising awareness through the school community was important, to maximise the legacy from the event and share it with others: 'Celebrate back in school, publish what they have achieved in school newsletters and blogs.' (Ellen, Biology teacher). Interestingly, for experienced teachers, discussing the way that knowledge gained at the conference impacted the research was also a key feature of maximising the impact of the event on the research itself, so that presentation was not seen as an end point, but more like a critical event or stimulus for the project: 'In the past this has changed the course of our research, after discussing the science with an academic.' (Nathan, Biology teacher).

While research was very often presented orally or through posters and displays, publication in scientific journals was only described as an outcome by two teachers. These teachers with experience of supporting students in writing peer-reviewed articles described their role as liaising with academics who are more familiar with this form of writing:

Most teachers would find it hard to write the paper because we are not familiar with the requirements of journals, which journals are likely to publish which kind of work and what the steps are to get something published. Some teachers could do it, but it would take far longer than with an expert who publishes work routinely. (Toby, Physics teacher)

Although teachers generally have less experience of disseminating research, they play an important role in identifying dissemination opportunities and brokering relationships with external mentors who can enable students to publish their research in peer-reviewed journals and present at conferences. In supporting students to develop working relationships with academic mentors, teachers model effective research collaborations, where individuals have different roles with complimentary areas of expertise.

\section{Discussion}

Although we have outlined the ten salient practices in turn, together they form an holistic pedagogy. Many of the activities which teachers engage in to support their high-school students in authentic research feature multiple practices simultaneously. The school context and the nature of the selected research project can impact on the pedagogic approach adopted, as can a teacher's own prior experience and interests. As a result of being asked about particular areas of their research mentoring practice, teachers reiterated a pedagogy which reflected the ten salient practices from undergraduate contexts, no new areas were identified specifically for schools, however, there was a difference in emphasis. As might be expected, teachers provided much greater support and framing 
for high-school students (salient practice 2) than academic mentors in higher education. They also provided much more guidance and modelling for students when networking (salient practice 8). Creating a sense of community (salient practice 5) was well developed by teachers as they tend to work with groups on projects. Interestingly this sense of research community is something that academics in university and college settings found the most challenging to develop (Walkington et al., 2018) outside of laboratory settings. As teachers are working with minors there are limits to the types of one to one (salient practice 6) and informal socialising (salient practice 5) that might be developed in schools, which contrasts to networking norms in higher education research contexts.

The interviews showed that some teachers identified particularly strongly as scientists, where being involved in the co-production of knowledge with their students was a great opportunity to reinforce their disciplinary interests and identity, as well as developing networks beyond their school. This corroborates earlier work on the 'teacher scientist' (Rushton \& Reiss, 2019). These teachers tended to emphasise the intellectual and professional socialisation forms of support (Thiry \& Laursen, 2011) that they offer through their mentoring in supporting the next generation of scientists, but also by actively doing science themselves. Other teachers were more focussed on student learning and the personal and emotional support that they provided through their mentoring, identifying more strongly as a 'teacher mentor'. This mentoring aspect of teacher identity, distinct from pastoral support, has a focus on supporting the personal and emotional aspects of research-based learning which requires perseverance and dealing with uncertainty. Both 'teacher scientists' and 'teacher mentors' recognised the benefits to their own career development of engaging in research mentoring, and the potential benefits for their students in transitioning into higher education. The balance between forms of mentoring support also differed according to projects, with some strongly focussed on outputs and tightly constrained by strong external framing, in contrast to more open-ended enquiry where student ownership of the research questions was possible and support could be more personalised, e.g. relating to student characteristics such as leadership. As teachers were mostly responsible for selecting projects, they could choose a project that would suit their mentoring interests, so from a professional development perspective this allowed flexibility.

We hope that in presenting the practices in turn they form a useful narrative that will support the training of teachers such that further research can be supported in schools. Projects outside of science or STEM would allow for teachers to identify as disciplinary practitioners or mentors. Uptake of IRIS projects has grown over the last three years and become more international (e.g. Australia, Belgium, and Norway) as well as being adopted in UK primary schools, so support for teachers' mentoring activity is essential to provide high quality experiences for pupils.

\section{Conclusion}

This research suggests that teachers benefit from working alongside their students, bringing science into schools which inspires others and builds enthusiasm. Mentoring can support professional development and enhance teacher motivation through being provided with a new challenge hand in hand with developing new disciplinary knowledge. In turn, teachers become more confident and outward looking through the development of professional networking, identifying as 'teacher scientists' (Rushton \& Reiss, 2019) and 'teacher mentors'.

Co-mentoring has huge potential for teacher professional development, our data showed that different forms of co-mentoring exist, including partnering of teachers with different levels of experience, pairing teachers and scientists, and sharing practice between schools who are engaged in the same project, as well as co-mentoring projects within a school but across disciplines so each teacher can contribute something relating to their own disciplinary or mentoring expertise. Technicians and teachers also benefit from co-mentoring in school-based research projects, each offering something different to students. However, new models of co-mentoring could also be created, including teaming up teachers who are new to the profession with an existing research project in school, and involving other learning support staff e.g. librarians, particularly if the research is in disciplines outside of science.

The ten salient practices for undergraduate mentoring have been used in workshops in the US, UK, South Africa and Germany to identify those in which they perceive high levels of confidence and expertise as well as what research mentors see as the most challenging practices (Walkington et al., 2018). We anticipate that the ten practices specific to high-school mentoring presented here could similarly form the basis of a reflective tool for continuing professional development for teachers, and also a useful framework for adoption in initial teacher education and in-school teacher training.

Future work will therefore focus on the impacts on student trajectories as a result of being mentored, particularly in terms of whether students go on to study science and /or STEM subjects; as well as whether a mentored 
experience better prepares students for higher education and easing the transition into more independent learning. An exploration of how mentoring might comprise a career benefit through a shift in identity from teacher to 'teacher mentor', 'teacher scientist' or 'teacher researcher' through fulfilling a need for ongoing embedded professional and broader career development and job satisfaction would be timely. This may contribute to addressing teacher retention challenges (Worth, 2018; Foster, 2019). The potential for mentor training and mentoring experiences to contribute to the professional development of teachers through recruitment, mid-career revitalisation and later career retention and advancement of teaching staff could also be explored.

\section{Acknowledgments}

The authors would like to thank the teachers and technicians who shared their experiences and to IRIS for their support of this research. This research did not receive any specific from funding agencies in the public, commercial, or not-for-profit sectors.

\section{References}

Albone, E., Collins, N., \& Hill, T. (1995). Scientific research in schools: A compendium of practical experience (Clifton: Clifton Scientific Trust).

Bell, T., Urhahne, D., Schanze, S., \& Ploetzner, R. (2010). Collaborative inquiry learning: Models, tools, and challenges. International Journal of Science Education, 32(3), 349-377. https://doi.org/10.1080/09500690802582241

Bennett, J., Dunlop, L., Knox, K. J., Reiss, M. J., \& Torrance-Jenkins, R. (2018). Practical Independent Research Projects in science: A synthesis and evaluation of the evidence of impact on high school students. International Journal of Science Education, 40, 1755-1773. https://doi.org/10.1080/09500693.2018.1511936

Elgren, T., \& Hensel, N. (2006). Undergraduate research experiences: Synergies between scholarship and teaching. Peer Review, 8, 4-7. Retrieved from https://search.proquest.com/docview/216599047?pq-origsite=gscholar

Elrod, S., Husic, D., \& Kinzie, J. (2010). Research and discovery across the curriculum. Peer Review, 12, 4. Retrieved from https://search.proquest.com/docview/734766996?pq-origsite=gscholar

Foster, D. (2019). Teacher recruitment and retention in England. House of Commons briefing paper No. 7222 。 Retrieved from http://researchbriefings.files.parliament.uk/documents/CBP-7222/CBP-7222.pdf

Furnell, W., Shenoy, A., Fox, E., \& Hatfield, P. (2018). First results from the LUCID-Timepix spacecraft payload onboard the TechDemoSat-1 satellite in LEO. Advances in Space Research, 63(5), 1523-1540. https://doi.org/10.1016/j.asr.2018.10.045

Gillies, S. L., \& Marsh, S. (2013). Doing science research at an undergraduate university. International Journal of Arts and Sciences, 6, 379-390.

Guest, G., MacQueen, K. M., \& Namey, E. E. (2012). Applied Thematic Analysis (Thousand Oaks, CA, Sage). https://doi.org/10.4135/9781483384436

Hall, E., Walkington, H., Shanahan, J., Ackley, E., \& Stewart, K. (2018a). Mentor perspectives on the place of undergraduate research mentoring in academic identity and career development: An analysis of award-winning mentors. International Journal for Academic Development, 23(1), 15-27. https://doi.org/10.1080/1360144X.2017.1412972

Hall, E., Walkington, H., Vandermaas-Peeler, M., Shanahan, J. O., Kolbech-Gudiksen, R., \& Mackenzie-Zimmer, M. (2018b). Enhancing short-term Undergraduate research experiences in Study Abroad: Curriculum design and mentor development. Perspectives on Undergraduate Research Mentoring 7.1. Retrieved from https://blogs.elon.edu/purm/2018/10/22/enhancing-short-term-undergraduate-research-experiences-in-study -abroad-curriculum-design-and-mentor-development-purm-7-1/

Healey, M., \& Jenkins, A. (2009). Developing undergraduate research and inquiry (York, Higher Education Academy).

Hensel, N. (2012). Characteristics of excellence in undergraduate research (Washington, DC, Council on Undergraduate Research).

Hill, J. L., \& Walkington, H. (2016). Developing Graduate Attributes through participation in undergraduate research conferences. Journal of Geography in Higher Education, 40(2), 222-237. https://doi.org/10.1080/03098265.2016.1140128 
IRIS (Institute for Research in Schools) (2019). Our Projects. Retrieved from http://www.researchinschools.org/our-projects.html

Ketcham, C., Hall, E., Fitzgibbon, H., \& Walkington, H. (2018). Co-mentoring in undergraduate research: a faculty development perspective, in: M. Vandermaas Peeler, P. Miller \& J. Moore, (Eds.), Excellence in Mentoring Undergraduate Research (pp. 155-179). Washington DC, USA, Council on Undergraduate Research.

Kneale, P., Edwards-Jones, A., Walkington, H., \& Hill, J. (2016). Evaluating undergraduate research conferences as vehicles for novice researcher development, International Journal for Researcher Development, 7(2), 159-177. https://doi.org/10.1108/IJRD-10-2015-0026

Kuh, G. (2008). High-impact educational practices: What they are, who has access to them, and why they matter (Washington, DC, Association of American Colleges and Universities).

Kuh, G., \& O'Donnell, K. (2013). Ensuring quality and taking high-impact practices to scale (Washington, DC, Association of American Colleges and Universities).

Larson, S., Partridge, L., Walkington, H., Wuetherick, B., \& Moore, J. (2018). An International Conversation about mentored undergraduate research and inquiry and academic development International Journal for Academic Development, 23(1), 6-14. https://doi.org/10.1080/1360144X.2018.1415033

Lombardi, M. M. (2007). Authentic learning for the 21st century: An overview. Educause Learning Initiative, 1, $1-12$.

Lopatto, D. (2010). Undergraduate research as a high-impact student experience. Peer Review, 12, 2-30. Retrieved from https://search.proquest.com/docview/734767118?pq-origsite=gscholar

Osborn, J. M., \& Karukstis, K. K. (2009). The benefits of undergraduate research, scholarship, and creative activity, in: M. Boyd \& J. Wesemann (Eds.), Broadening Participation in Undergraduate Research: Fostering Excellence and Enhancing the Impact (pp. 41-53). Washington, DC, Council on Undergraduate Research.

Parker, B., Fox, E., \& Rushton, E.A.C. (2018). IRIS - promoting young peoples' participation and attainment in STEM and reigniting teachers' passion for science education. Impact, 2. Retrieved from https://impact.chartered.college/article/parker-iris-stem-students-teachers-participation-research/.

Parker, B., Thomas, L., Rushton, E.A.C., \& Hatfield, P. (2019). Transforming Education with the Timepix detector - ten years of CERN@school. Radiation Measurements. https://doi.org/10.1016/j.radmeas.2019.03.008

Reiss, M. J. (1992). School ecology practicals, in: D. Harding (Complier) Ecology Projects. Ideas and practicals from the Journal of biological education. Institute of Biology p.1-2.

Roth, W. M. (1995). Authentic school science knowing and learning in open-inquiry science laboratories (The Netherlands: Kluwer). https://doi.org/10.1007/978-94-011-0495-1

Rushton, E. A. C., \& Reiss, M. J. (2019). From science teacher to 'teacher scientist': exploring the experiences of research-active science teachers in the UK. International Journal of Science Education, 41(11) 1541-1561. https://doi.org/10.1080/09500693.2019.1615656

Shanahan, J., Ackley-Holbrook, E., Hall, E., Stewart, K., \& Walkington, H. (2015). Salient Practices of Undergraduate Research Mentors: A Review of the Literature. Mentoring and Tutoring, 23(5), 359-376. https://doi.org/10.1080/13611267.2015.1126162

Shanahan, J., Ackley-Holbrook, E., Hall, E., Stewart, K., \& Walkington, H. (2016). 'Ten Salient Practices of Undergraduate Research Mentors' Paper presented at the National Conference on Undergraduate Research, University of North Carolina, Asheville, USA.

Shanahan, J. O., Walkington, H., Ackley, E., Hall, E., \& Stewart, K. (2017). Award winning mentors see democratization as the future of undergraduate research, Council on Undergraduate Research Quarterly, 37(4), 4-11. https://doi.org/10.18833/curq/37/4/14

Thiry, H., \& Laursen, S. L. (2011). The role of student-advisor interactions in apprenticing undergraduate researchers into a scientific community of practice. Journal of Science Education and Technology, 20, 771-784. https:// doi.org/10.1080/00221546.2011.11777209

Walkington, H., Stewart, K. A., Hall, E. E., Ackley, E., \& Shanahan, J. O. (2019). Salient practices of 
award-winning undergraduate research mentors-balancing freedom and control to achieve excellence. Studies in Higher Education, 1-14. https://doi.org/10.1080/03075079.2019.1637838

Walkington, H., Hall, E., Shanahan, J. Ackley, E., \& Stewart, K. (2018). Striving for excellence in mentoring undergraduate research: The challenges and approaches to ten salient practices, in: M. Vandermaas Peeler, P. Miller \& J. Moore, (Eds.), Excellence in Mentoring Undergraduate Research (pp. 105-125). Washington DC, USA, Council on Undergraduate Research.

Walkington, H., Hill, J. L., \& Kneale, P. E. (2016). Reciprocal Elucidation: a student led pedagogy in multidisciplinary undergraduate research conferences. Higher Education Research and Development, 36(2), 416-429. https://doi.org/10.1080/07294360.2016.1208155

Whyntie, T., \& Harrison, M. A. (2014). Simulation and analysis of the LUCID experiment in the Low Earth Orbit radiation environment. Journal of Physics: Conference Series, 513(2), p.022038. https://doi.org/10.1088/1742-6596/513/2/022038

Whyntie, T., \& Harrison, M. A. (2015). Full simulation of the LUCID experiment in the Low Earth Orbit radiation environment. Journal of Instrumentation, 10(03), p.C03043. https://doi.org/10.1088/1748-0221/10/03/C03043

Worth, J. (2018). Latest teacher retention statistics paint a bleak picture for teacher supply in England. National Foundation for Educational Research (NFER). Retrieved from https://www.nfer.ac.uk/news-events/nfer-blogs/latest-teacher-retention-statistics-paint-a-bleak-picture-for-te acher-supply-in-england

\section{Notes}

Note 1. Students in English and Scottish High Schools are aged 11-18 years. English students usually complete seven years of high school education with exams at the end of the fifth year (General Certificate of Secondary Education) in eight to twelve subjects with mostly compulsory and some elective subjects, and exams at the end of the seventh year (Advanced Levels) in two to four elective subjects. The education system is similar in Scotland however students usually complete six years of high school education (with an additional year in higher education), and have exams at the end of fourth (Nationals), fifth (Highers) and sixth (Advanced Highers) years, with a similar progression from mostly compulsory subjects to greater subject choice.

Note 2. An Extended Project Qualification (EPQ) is usually taken by students in their final year of high school and is equivalent to half an Advanced Level qualification. The project enables students to undertake largely self-directed and self-motivated study where, with teacher support, they select a topic, undertake research and produce either a written report, artefact (e.g. an artwork) or production (e.g. a fashion show). CREST awards are an extra-curricular scheme delivered by the British Science Association for over thirty years, to support school student science investigations at three levels (Bronze, Silver, Gold) At each level the time required and student independence increases. Each year approximately 30,000 students complete an EPQ and a further 30,000 students achieve a CREST award across the three levels.

\section{Copyrights}

Copyright for this article is retained by the author(s), with first publication rights granted to the journal.

This is an open-access article distributed under the terms and conditions of the Creative Commons Attribution license (http://creativecommons.org/licenses/by/4.0/). 